\title{
Seismic history analysis of asymmetrical adjacent buildings with soil-structure interaction consideration
}

\author{
M. E. Uz \& M. N. S. Hadi \\ School of Civil, Mining and Environmental Engineering, \\ University of Wollongong, NSW, Australia
}

\begin{abstract}
The seismic response history analysis of multi-storey asymmetric adjacent buildings with soil-structure interaction (SSI) during impact is investigated in this study. The coupled multi-degree of freedom modal differential equations of motion for the two way asymmetric shear buildings are derived and solved using a step by step solution by the fourth-order Runge-Kutta method with impact and without impact. The SSI forces are modelled in the form of the frequencyindependent soil springs and dashpots. A numerical example of two-way asymmetric four-storey adjacent buildings under the variation of the important SSI system parameters such as the large and small SSI effects is investigated under the excitation of the $1940 \mathrm{El}$ Centro Earthquake. This study shows that the lateral torsion response of both buildings is affected when impact takes place with the adjacent buildings. The first three modal response histories of each building are significantly reduced due to the effect of the small SSI. Further, it is also observed that the roof twist of the lighter buildings is decreased for the large SSI effect compared to the small SSI effect. Finally, in increased eccentricities, the impact response of buildings is significantly severe.

Keywords: earthquake engineering, impact effects, soil-structure interaction, asymmetry.
\end{abstract}

\section{Introduction}

Providing the required separation distance is not always possible. Many researchers have investigated the pounding problem of seismic analysis of two way asymmetric buildings with soil-structure interaction under the two 
directional ground motions [1-5]. In these studies, to deal with the nonproportional damping of the SSI systems, equivalent modal damping was calculated to facilitate the modal response history analysis. The equivalent modal damping was estimated by either quantifying the dissipated energy in the soil [6] or matching the approximation approaches normal mode solution with the rigorous solution for a certain structural location [3]. For engineering applications without the need for calculating the complicated equivalent modal damping, a simple and real valued modal response history analysis has been developed [7]. Moreover, the effects of both the SSI systems and pounding on the coupled buildings under strong earthquakes have not been investigated fully. The aim of this study is to conduct a comparative study in order to investigate the SSI effect onto adjacent buildings considering the effect of pounding. Based on the fourth order Runge-Kutta method, a MATLAB program is developed to solve the equations of motion for the SSI systems of coupled buildings subjected to pounding effects under the excitations of earthquake ground acceleration and numerical simulations presented are used. The issue of the pounding of bidirectional asymmetric adjacent buildings with the SSI systems is not familiar with the complex-valued seismic analysis procedures in the frequency domain $[8,9]$. A response history analysis procedure considering of both effects is proposed using the MDOF modal equations of the motion by watching the solutions of equations of motions for the whole SSI systems and pounding on the adjacent buildings in the following numerical examples.

\section{Theoretical background of system model}

In order to consider the effects of the large and small SSI systems, two-way asymmetric coupled buildings are modelled in this study. To validate the equation of motion for the whole SSI system comparing to the multi-degrees of freedom modal equations of the motion, a modal analysis study is conducted herein. The interaction forces at the soil-structure interface are simulated using frequency-independent spring and dashpot set in parallel [10]. The rectangular dimensions of foundations for both buildings are converted as circular footings in order to adopt the frequency independent spring and dashpot set. The simplified model of $\mathrm{N}$ - and S- storey coupled buildings resting on the surface of an elastic half-space is shown in Figure 1 . For $\mathrm{i}=(1,2, ., \mathrm{N})$ and $\mathrm{j}=(1,2, ., \mathrm{S})$, $\mathrm{m}_{\mathrm{i}}, \mathrm{k}_{\mathrm{xi}}, \mathrm{c}_{\mathrm{xi}}, \mathrm{k}_{\mathrm{yi}}, \mathrm{c}_{\mathrm{yi}}, \mathrm{I}_{\mathrm{xi}}$ and $\mathrm{I}_{\mathrm{yi}}$ are the mass, the elastic structural stiffness, damping coefficients and moments of inertia of the related floor about the axes through the centre of mass $(\mathrm{CM})$ and parallel to the $\mathrm{x}$ and $\mathrm{y}$ axes for Building $\mathrm{A}$ and Building B, respectively. The subscripts $\mathrm{i}$ and $\mathrm{j}$ in Figure 1 are the storey number of the buildings that denote $1,2, ., \mathrm{N}$ for Building $\mathrm{A}$ and $1,2, ., \mathrm{S}$ for Building B. Moreover, the subscripts and superscripts of $a$ and $b$ symbolize Building $\mathrm{A}$ and Building $\mathrm{B}$, respectively. For the horizontal component of ground motion assumed to be uniform over the base of the buildings, the total number of degrees of freedom is $3 \mathrm{~N}+5$ for $\mathrm{N}$-storey building and therefore $3 \mathrm{~N}+5$ and $3 \mathrm{~S}+5$ equations are required for both Building $\mathrm{A}$ and Building $\mathrm{B}$, 

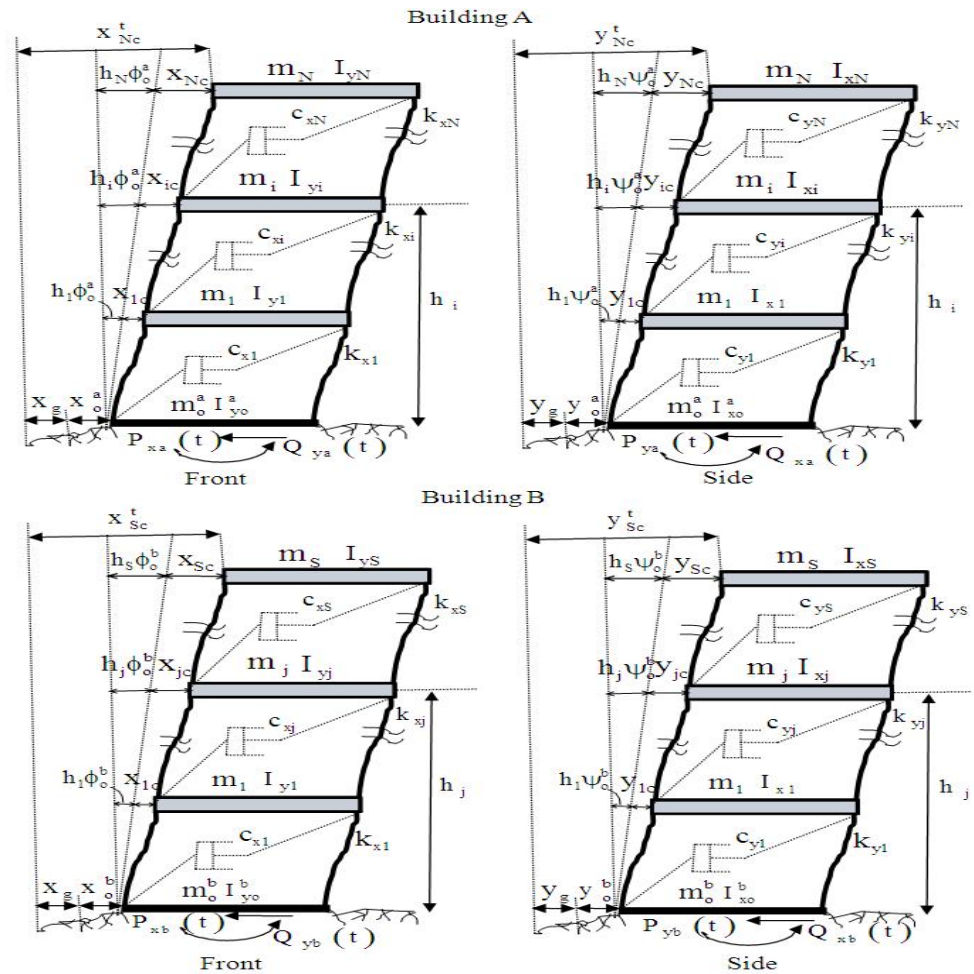

Figure 1: Elevation of dynamic model for asymmetric adjacent shear buildings.

respectively. Equations for Building B are the same as shown below for Building A associated with the number of storey (j) of Building B.

Hence, only the equations of Building A are expressed here. Translation in the longitudinal (x) and transverse $(\mathrm{y})$ directions and rotation about the $\mathrm{CM}$ of these equations may be expressed as shown in Eqn. (1). As an example, for Nstorey Building A, the total number of degrees of freedom, $3 \mathrm{~N}+5$ are obtained as $3 \mathrm{~N}$ equations of dynamic equilibrium of each floor of the superstructure for the translation in the $\mathrm{x}$ and $\mathrm{y}$ directions and rotation about the centre of mass and 5 degrees of freedom due to interaction at the foundation. The $3 \mathrm{~N}$ equations of dynamic equilibrium of each floor of Building A may be expressed as

$$
\begin{gathered}
{\left[\mathrm{M}_{\mathrm{a}}\right]\left\{\ddot{\mathrm{x}}_{\mathrm{ic}}^{\mathrm{t}}\right\}+\left[\mathrm{C}_{\mathrm{ax}}\right]\left\{\dot{\mathrm{x}}_{\mathrm{i}}\right\}+\left[\mathrm{K}_{\mathrm{ax}}\right]\left\{\mathrm{x}_{\mathrm{i}}\right\}+\left[\mathrm{F}_{\mathrm{xij}}^{\mathrm{p}}(\mathrm{t})\right]=\{0\}} \\
{\left[\mathrm{M}_{\mathrm{a}}\right]\left\{\ddot{\mathrm{y}}_{\mathrm{ic}}^{\mathrm{t}}\right\}+\left[\mathrm{C}_{\mathrm{ay}}\right]\left\{\dot{\mathrm{y}}_{\mathrm{i}}\right\}+\left[\mathrm{K}_{\mathrm{ay}}\right]\left\{\mathrm{y}_{\mathrm{i}}\right\}+\left[\mathrm{F}_{\mathrm{yij}}^{\mathrm{p}}(\mathrm{t})\right]=\{0\}} \\
\mathrm{r}_{\mathrm{a}}^{2}\left[\mathrm{M}_{\mathrm{a}}\right]\left\{\ddot{\theta}_{\mathrm{i}}^{\mathrm{t}}\right\}+\mathrm{f}_{\mathrm{a}}\left[\mathrm{C}_{\mathrm{ax}}\right]\left\{\dot{\mathrm{x}}_{\mathrm{i}}\right\}-\mathrm{e}_{\mathrm{a}}\left[\mathrm{C}_{\mathrm{ay}}\right]\left\{\dot{\mathrm{y}}_{\mathrm{i}}\right\}+\left[\mathrm{C}_{\theta \mathrm{R}}^{\mathrm{a}}\right]\left\{\dot{\theta}_{\mathrm{ic}}\right\}+\mathrm{f}_{\mathrm{a}}\left[\mathrm{K}_{\mathrm{ax}}\right]\left\{\mathrm{x}_{\mathrm{i}}\right\}-\mathrm{e}_{\mathrm{a}}\left[\mathrm{K}_{\mathrm{ay}}\right]\left\{\mathrm{y}_{\mathrm{i}}\right\} \\
+\left[\mathrm{K}_{\theta \mathrm{R}}^{\mathrm{a}}\right]\left\{\theta_{\mathrm{ic}}\right\}+\left[\mathrm{F}_{\theta \mathrm{ij}}^{\mathrm{p}}(\mathrm{t})\right]=\{0\}
\end{gathered}
$$


where $\mathrm{M}_{\mathrm{a}}, \mathrm{C}_{\mathrm{ax}}, \mathrm{K}_{\mathrm{ax}}, \mathrm{C}_{\mathrm{ay}}$ and $\mathrm{K}_{\mathrm{ay}}$ are the $\mathrm{N} \times \mathrm{N}$ sub-matrices of mass, damping and lateral stiffness in the $\mathrm{x}$ and $\mathrm{y}$ directions of Building $\mathrm{A}$, respectively. $\mathrm{x}_{\mathrm{ic}}^{\mathrm{t}}, \mathrm{y}_{\mathrm{ic}}^{\mathrm{t}}$ and $\theta_{i}^{t}$ are the total displacements of centre of mass of the floors in the longitudinal and transverse directions, and the total twist of the floors about the vertical axis $(\mathrm{z})$ in Building $\mathrm{A}$, respectively. $\mathrm{F}_{\mathrm{xij}}^{\mathrm{P}}(\mathrm{t})$ denotes the pounding forces in the $\mathrm{x}$ direction with the help of the non-linear viscoelastic model [11]. $\mathrm{F}_{\mathrm{yij}}^{\mathrm{P}}(\mathrm{t})$ and $\mathrm{F}_{\theta i \mathrm{j}}^{\mathrm{P}}(\mathrm{t})$ have been considered by the Coulomb friction model $[12,13] . \mathrm{x}_{\mathrm{i}}, \mathrm{y}_{\mathrm{i}}$ and $\theta_{i c}$ are the displacement vectors with respect to the base in the $\mathrm{x}$ and $\mathrm{y}$ directions of the centre of resistance $(\mathrm{CR})$ and the twist of the floors with respect to the base. Moreover, two way asymmetric buildings are modelled as the CR being not coincident with the CM along the two horizontal plane axes. The static eccentricities of the centre of resistance from the centre of mass (e and f) in the $x$ and $\mathrm{y}$ axes are the same for each floor deck, although the CR may vary from storey to storey. Hence, the CR associated with the adjacent buildings is assumed to lie at eccentricities $e_{a}, f_{a}$ for Building $A$ and $e_{b}, f_{b}$ for Building $B$. The radii of gyration $\left(r_{a}\right.$ and $\left.r_{b}\right)$ of any rigid floor decks are about the centre of mass for each building. $\mathrm{K}_{\theta \mathrm{R}}^{\mathrm{a}}$ and $\mathrm{K}_{\theta \mathrm{M}}^{\mathrm{a}}$ in Eqns. (1) and (2) are the torsional stiffness matrix defined about the $\mathrm{CR}$ and the $\mathrm{CM}$, respectively. Furthermore, $\mathrm{C}_{\mathrm{ax}}, \mathrm{C}_{\mathrm{ay}}$ and $\mathrm{C}_{\theta \mathrm{R}}^{\mathrm{a}}$ in Eqn. (1) are the damping matrices for Building $\mathrm{A}$, assumed to be proportional to the stiffness matrices as defined in Eqn. (2).

$$
\begin{gathered}
{\left[\mathrm{K}_{\theta \mathrm{M}}^{\mathrm{a}}\right]=\left[\mathrm{K}_{\theta \mathrm{R}}^{\mathrm{a}}\right]+\mathrm{e}_{\mathrm{a}}^{2}\left[\mathrm{~K}_{\mathrm{ay}}\right]+\mathrm{f}_{\mathrm{a}}^{2}\left[\mathrm{~K}_{\mathrm{ax}}\right]} \\
{\left[\mathrm{C}_{\mathrm{ax}}\right]=\alpha\left[\mathrm{K}_{\mathrm{ax}}\right],\left[\mathrm{C}_{\mathrm{ay}}\right]=\alpha\left[\mathrm{K}_{\mathrm{ay}}\right] \text { and }\left[\mathrm{C}_{\theta \mathrm{R}}^{\mathrm{a}}\right]=\alpha\left[\mathrm{K}_{\theta \mathrm{R}}^{\mathrm{a}}\right]}
\end{gathered}
$$

in which $\alpha$ is a constant value in terms of the ratio of the coefficient and stiffness of the buildings. The displacement vectors in the related directions of Building A without SSI effects can be defined by Eqn. (3).

$$
\begin{aligned}
& \left\{\mathrm{x}_{\text {ic }}\right\}=\left\{\mathrm{x}_{\mathrm{i}}\right\}-\mathrm{f}_{\mathrm{a}}\left\{\theta_{\text {ic }}\right\},\left\{\dot{\mathrm{x}}_{\mathrm{ic}}\right\}=\left\{\dot{\mathrm{x}}_{\mathrm{i}}\right\}-\mathrm{f}_{\mathrm{a}}\left\{\dot{\theta}_{\text {ic }}\right\},\left\{\ddot{\mathrm{x}}_{\mathrm{ic}}\right\}=\left\{\ddot{\mathrm{x}}_{\mathrm{i}}\right\}-\mathrm{f}_{\mathrm{a}}\left\{\ddot{\theta}_{\text {ic }}\right\} \\
& \left\{\mathrm{y}_{\mathrm{ic}}\right\}=\left\{\mathrm{y}_{\mathrm{i}}\right\}+\mathrm{e}_{\mathrm{a}}\left\{\theta_{\text {ic }}\right\},\left\{\dot{\mathrm{y}}_{\text {ic }}\right\}=\left\{\dot{\mathrm{y}}_{\mathrm{i}}\right\}+\mathrm{e}_{\mathrm{a}}\left\{\dot{\theta}_{\text {ic }}\right\},\left\{\ddot{\mathrm{y}}_{\mathrm{ic}}\right\}=\left\{\ddot{\mathrm{y}}_{\mathrm{i}}\right\}+\mathrm{e}_{\mathrm{a}}\left\{\ddot{\theta}_{\text {ic }}\right\}
\end{aligned}
$$

where $\mathrm{x}_{\mathrm{ic}}$ and $\mathrm{y}_{\mathrm{ic}}$ are displacement vectors of degrees of freedom of superstructure about the CM. $x_{i c}^{t}, y_{i c}^{t}$ and $\theta_{i c}^{t}$ can be expressed in view of the following relationship of $x_{i c}^{\prime}$ and $y_{i c}^{\prime}$ vectors, which are the degrees of freedom of the superstructure defined as in Eqn. (4).

$$
\begin{gathered}
\left\{\mathrm{x}_{\mathrm{ic}}^{\mathrm{t}}\right\}=\mathrm{x}_{\mathrm{o}}^{\mathrm{a}}\{1\}+\mathrm{x}_{\mathrm{g}}\{1\}+\varphi_{\mathrm{o}}^{\mathrm{a}}\left\{\mathrm{h}_{\mathrm{i}}\right\}+\left\{\mathrm{x}_{\mathrm{ic}}\right\} \text { and }\left\{\mathrm{x}_{\mathrm{ic}}^{\prime}\right\}=\mathrm{x}_{\mathrm{o}}^{\mathrm{a}}\{1\}+\varphi_{\mathrm{o}}^{\mathrm{a}}\left\{\mathrm{h}_{\mathrm{i}}\right\}+\left\{\mathrm{x}_{\mathrm{ic}}\right\} \\
\left\{\mathrm{y}_{\mathrm{ic}}^{\mathrm{t}}\right\}=\mathrm{y}_{\mathrm{o}}^{\mathrm{a}}\{1\}+\mathrm{y}_{\mathrm{g}}\{1\}+\psi_{\mathrm{o}}^{\mathrm{a}}\left\{\mathrm{h}_{\mathrm{i}}\right\}+\left\{\mathrm{y}_{\mathrm{ic}}\right\} \text { and }\left\{\mathrm{y}_{\mathrm{ic}}^{\prime}\right\}=\mathrm{y}_{\mathrm{o}}^{\mathrm{a}}\{1\}+\psi_{\mathrm{o}}^{\mathrm{a}}\left\{\mathrm{h}_{\mathrm{i}}\right\}+\left\{\mathrm{y}_{\mathrm{ic}}\right\} \\
\left\{\theta_{\mathrm{i}}^{\mathrm{t}}\right\}=\theta_{\mathrm{o}}^{\mathrm{a}}\{1\}+\left\{\theta_{\mathrm{ic}}\right\}
\end{gathered}
$$


where $\mathrm{x}_{0}^{\mathrm{a}}, \mathrm{y}_{\mathrm{o}}^{\mathrm{a}}, \psi_{\mathrm{o}}^{\mathrm{a}}$ and $\varphi_{\mathrm{o}}^{\mathrm{a}}$ are the degrees of freedom at the base associated with translations and rocking about the $\mathrm{x}$ and $\mathrm{y}$ axes, respectively. $\theta_{\mathrm{o}}^{\mathrm{a}}$ is the twist about the $\mathrm{z}$ axis. After substituting in Eqns. (2), (3) and (4), and rearranging into to Eqn. (1), a more concise form for the $3 \mathrm{~N} \times 3 \mathrm{~N}$ sub-matrices of the superstructure resting on a rigid base on the left upper corner of $\mathrm{M}^{\mathrm{a}}, \mathrm{C}^{\mathrm{a}}$ and $\mathrm{K}^{\mathrm{a}}$ can be written herein. With reference to Figure 1, the equation of motion for the whole foundation system for Building A can be written for the translation in the $\mathrm{x}$ and $\mathrm{y}$ axes, twist about the $\mathrm{z}$ axis and rocking about the $\mathrm{x}$ and $\mathrm{y}$ axes, respectively as shown in Eqn. (5) [10].

$$
\begin{gathered}
\mathrm{m}_{\mathrm{o}}^{\mathrm{a}}\left(\ddot{\mathrm{x}}_{\mathrm{g}}+\ddot{\mathrm{x}}_{\mathrm{o}}^{\mathrm{a}}\right)+\{1\}^{\mathrm{T}}\left[\mathrm{M}_{\mathrm{a}}\right]\left\{\ddot{\mathrm{x}}_{\mathrm{ic}}^{\mathrm{t}}\right\}+\mathrm{P}_{\mathrm{xa}}(\mathrm{t})=0 \\
\mathrm{~m}_{\mathrm{o}}^{\mathrm{a}}\left(\ddot{\mathrm{y}}_{\mathrm{g}}+\ddot{\mathrm{y}}_{\mathrm{o}}^{\mathrm{a}}\right)+\{1\}^{\mathrm{T}}\left[\mathrm{M}_{\mathrm{a}}\right]\left\{\ddot{\mathrm{y}}_{\mathrm{yc}}^{\mathrm{t}}\right\}+\mathrm{P}_{\mathrm{ya}}(\mathrm{t})=0 \\
\mathrm{r}_{\mathrm{a}}^{2} \mathrm{~m}_{\mathrm{o}}^{\mathrm{a}} \ddot{\ddot{o}}_{\mathrm{o}}^{\mathrm{a}}+\mathrm{r}_{\mathrm{a}}^{2}\{1\}^{\mathrm{T}}\left[\mathrm{M}_{\mathrm{a}}\right]\left\{\ddot{\theta}_{\mathrm{i}}^{\mathrm{t}}\right\}+\mathrm{T}_{\mathrm{a}}(\mathrm{t})=0 \\
\sum_{\mathrm{i}=0}^{\mathrm{N}} \mathrm{I}_{\mathrm{xi}} \ddot{\Psi}_{\mathrm{o}}^{\mathrm{a}}+\left\{\mathrm{h}_{\mathrm{i}}\right\}^{\mathrm{T}}\left[\mathrm{M}_{\mathrm{a}}\right]\left\{\ddot{\mathrm{y}}_{\mathrm{ic}}^{\mathrm{t}}\right\}+\mathrm{Q}_{\mathrm{xa}}(\mathrm{t})=0 \\
\sum_{\mathrm{i}=0}^{\mathrm{N}} \mathrm{I}_{\mathrm{yi}} \ddot{\varphi}_{\mathrm{o}}^{\mathrm{a}}+\left\{\mathrm{h}_{\mathrm{i}}\right\}^{\mathrm{T}}\left[\mathrm{M}_{\mathrm{a}}\right]\left\{\ddot{\mathrm{x}}_{\mathrm{ic}}^{\mathrm{t}}\right\}+\mathrm{Q}_{\mathrm{ya}}(\mathrm{t})=0
\end{gathered}
$$

where $I_{x i}$ and $I_{y i}$ are moments of inertia of the $i^{\text {th }}$ floor about the axis through the $\mathrm{CM}$ and parallel to the longitudinal and transverse directions, respectively. $\mathrm{m}_{\mathrm{o}}^{\mathrm{a}}$ is the mass of the foundation of Building A. $h_{\mathrm{i}}$ and $h_{j}$ are the column vector composed of the storey heights of Building A and Building B throughout the foundation to each floor, respectively. Earthquake ground accelerations in the $x$ and y directions are shown as $\ddot{x}_{g}$ and $\ddot{y}_{g}$, respectively. $P_{x a}(t), P_{y a}(t), T_{a}(t), Q_{x a}(t)$ and $\mathrm{Q}_{\mathrm{ya}}(\mathrm{t})$ are the interaction forces of Building $\mathrm{A}$ based on frequencyindependent soil springs and dashpots as shown in Eqn.(5) [4]. The definitions of spring and dashpot constants of the static impedance functions are clearly presented with various subscripts [10]. First assume that two buildings remain in the linear elastic range and hence they do not yield under earthquake excitation. In such a case, the equation of motion in Eqn. (6) for the couple buildings with the whole interactions such as the SSI, torsional coupling and the pounding involved responses of adjacent buildings modelled with elastic systems at each floor level as system is

$$
\left[\begin{array}{cc}
M^{a} & 0 \\
0 & M^{b}
\end{array}\right]\left\{\begin{array}{l}
\ddot{U}^{a}(t) \\
\ddot{U}^{b}(t)
\end{array}\right\}+\left[\begin{array}{cc}
C^{a} & 0 \\
0 & C^{b}
\end{array}\right]\left\{\begin{array}{c}
\dot{U}^{a}(t) \\
\dot{U}^{b}(t)
\end{array}\right\}+\left[\begin{array}{cc}
K^{a} & 0 \\
0 & K^{b}
\end{array}\right]\left\{\begin{array}{c}
U^{a}(t) \\
U^{b}(t)
\end{array}\right\}+\left\{\begin{array}{c}
F^{p}(t) \\
-F^{p}(t)
\end{array}\right\}=-\left\{\begin{array}{c}
P^{a}(t) \\
P^{b}(t)
\end{array}\right\}
$$

where $\mathrm{M}^{\mathrm{a}}, \mathrm{C}^{\mathrm{a}}, \mathrm{K}^{\mathrm{a}}, \mathrm{M}^{\mathrm{b}}, \mathrm{C}^{\mathrm{b}}$ and $\mathrm{K}^{\mathrm{b}}$ are the mass, damping and stiffness matrices of couple buildings, respectively. Moreover, $F^{p}(t), P^{a}(t)$ and $P^{b}(t)$ are vectors containing the forces due to impact between floors with masses $m_{i}, m_{j}$ and loading of the adjacent buildings in that order (see Eqns. (7), (8) and (9)). $\ddot{\mathrm{U}}^{\mathrm{a}}(\mathrm{t}), \dot{\mathrm{U}}^{\mathrm{a}}(\mathrm{t}), \mathrm{U}^{\mathrm{a}}(\mathrm{t}), \ddot{\mathrm{U}}^{\mathrm{b}}(\mathrm{t}), \dot{\mathrm{U}}^{\mathrm{b}}(\mathrm{t})$ and $\mathrm{U}^{\mathrm{b}}(\mathrm{t})$ are the vectors of acceleration, velocity and displacement of the system respectively. 


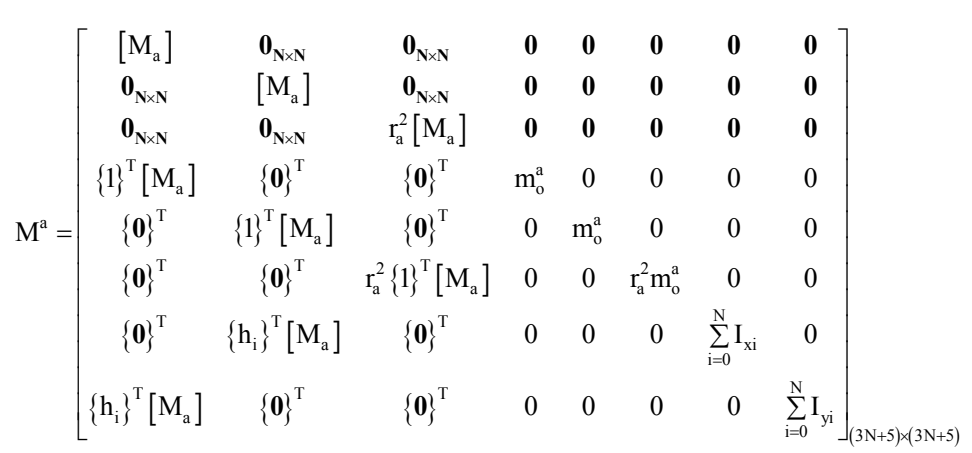

where $\mathbf{0}$ and 1 are the $\mathrm{N} \times 1$ column vectors whose elements are equal to zero and one, respectively.

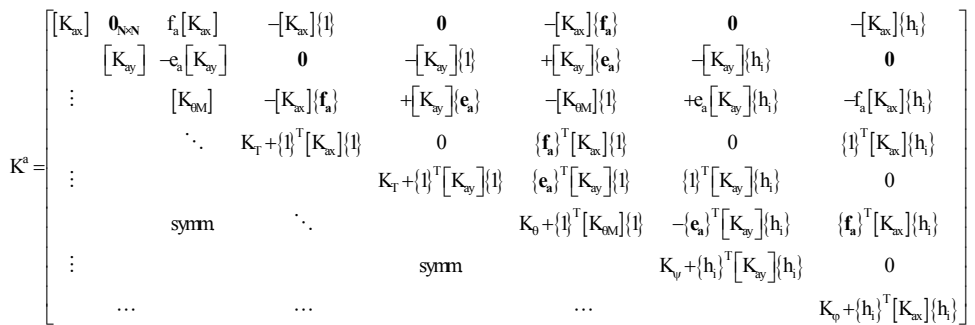

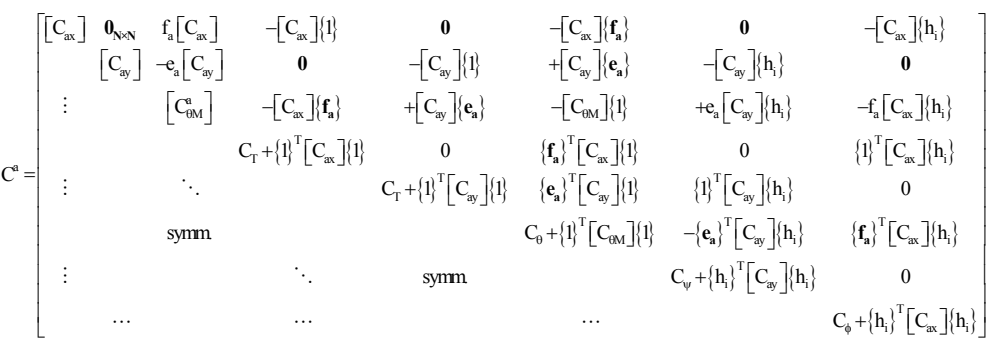

$$
\begin{aligned}
& \mathrm{P}^{\mathrm{a}}(\mathrm{t})=\left\{\begin{array}{c}
{\left[\mathrm{M}_{\mathrm{a}}\right]\{1\} \ddot{\mathrm{x}}_{\mathrm{g}}} \\
{\left[\mathrm{M}_{\mathrm{a}}\right]\{1\} \ddot{\mathrm{y}}_{\mathrm{g}}} \\
\mathbf{0} \\
\left(\mathrm{m}_{\mathrm{o}}^{\mathrm{a}}+\{1\}^{\mathrm{T}}\left[\mathrm{M}_{\mathrm{a}}\right]\right) \ddot{\mathrm{x}}_{\mathrm{g}} \\
\left(\mathrm{m}_{\mathrm{o}}^{\mathrm{a}}+\{1\}^{\mathrm{T}}\left[\mathrm{M}_{\mathrm{a}}\right]\right) \ddot{\mathrm{y}}_{\mathrm{g}} \\
0 \\
\left\{\mathrm{~h}_{\mathrm{i}}\right\}^{\mathrm{T}}\left[\mathrm{M}_{\mathrm{a}}\right] \ddot{\mathrm{y}}_{\mathrm{g}} \\
\left\{\mathrm{h}_{\mathrm{i}}\right\}^{\mathrm{T}}\left[\mathrm{M}_{\mathrm{a}}\right] \ddot{\mathrm{x}}_{\mathrm{g}}
\end{array}\right\}_{(3 \mathrm{~N}+5) \times 1}\left(\begin{array}{c}
{\left[\mathrm{x}_{\mathrm{ic}}^{\prime}\right]} \\
{\left[\mathrm{y}_{\mathrm{ic}}^{\prime}\right]} \\
{\left[\theta_{\mathrm{i}}^{\mathrm{t}}\right]} \\
\mathrm{x}_{\mathrm{o}}^{\mathrm{a}} \\
\mathrm{y}_{\mathrm{o}}^{\mathrm{a}} \\
\theta_{\mathrm{o}}^{\mathrm{a}} \\
\psi_{\mathrm{o}}^{\mathrm{a}} \\
\phi_{\mathrm{o}}^{\mathrm{a}}
\end{array}\right\}_{(3 \mathrm{~N}+5) \times 1} \quad, \quad \mathrm{~F}^{\mathrm{a}}(\mathrm{t})=\left\{\begin{array}{c}
{\left[\mathrm{F}_{\mathrm{xij}}^{\mathrm{P}}(\mathrm{t})\right]} \\
{\left[\mathrm{F}_{\mathrm{yij}}^{\mathrm{P}}(\mathrm{t})\right]} \\
{\left[\mathrm{F}_{\theta i j}^{\mathrm{P}}(\mathrm{t})\right]} \\
0 \\
0 \\
0 \\
0 \\
0
\end{array}\right\}_{(3 \mathrm{~N}+5) \times 1}
\end{aligned}
$$

For simulating the pounding force during impact $F_{x i j}^{P}, F_{\theta i j}^{P}(i=1,2, . . N ; j=1,2, . ., S)$, the nonlinear viscoelastic model is used between the storey levels of the two adjacent buildings, which is based on the following formula in Eqn. (10) as both approach period and restitution period of collisions $[11,14]$. 


$$
\begin{gathered}
\mathrm{F}_{\mathrm{xij}}^{\mathrm{p}}(\mathrm{t})=0 \text { for } \delta_{\mathrm{ij}}(\mathrm{t}) \leq 0 ; \\
\mathrm{F}_{\mathrm{xij}}^{\mathrm{p}}(\mathrm{t})=\bar{\beta}\left(\delta_{\mathrm{ij}}(\mathrm{t})\right)^{3 / 2}+\overline{\mathrm{c}}_{\mathrm{ij}}(\mathrm{t}) \dot{\delta}_{\mathrm{ij}}(\mathrm{t}) \text { for } \delta_{\mathrm{ij}}(\mathrm{t})>0 \text { and } \dot{\delta}_{\mathrm{ij}}(\mathrm{t})>0 ; \\
\mathrm{F}_{\mathrm{xij}}^{\mathrm{p}}(\mathrm{t})=\bar{\beta}\left(\delta_{\mathrm{ij}}(\mathrm{t})\right)^{3 / 2} \text { for } \delta_{\mathrm{ij}}(\mathrm{t})>0 \text { and } \dot{\delta}_{\mathrm{ij}}(\mathrm{t}) \leq 0 ; \\
\overline{\mathrm{c}}_{\mathrm{ij}}(\mathrm{t})=2 \bar{\xi} \sqrt{\bar{\beta} \sqrt{\delta_{\mathrm{ij}}(\mathrm{t})} \frac{\mathrm{m}_{\mathrm{i}} \mathrm{m}_{\mathrm{j}}}{\mathrm{m}_{\mathrm{i}}+\mathrm{m}_{\mathrm{j}}}} ; \\
\bar{\xi}=\frac{9 \sqrt{5}}{2} \frac{1-\mathrm{e}^{2}}{\mathrm{e}(\mathrm{e}(9 \pi-16)+16)} \\
\delta_{\mathrm{ij}}(\mathrm{t})=\mathrm{x}_{\mathrm{ic}}^{\prime}(\mathrm{t})-\mathrm{x}_{\mathrm{jc}}^{\prime}(\mathrm{t})-\mathrm{D} ; \\
\dot{\delta}_{\mathrm{ij}}(\mathrm{t})=\dot{\mathrm{x}}_{\mathrm{ic}}^{\prime}(\mathrm{t})-\mathrm{x}_{\mathrm{jc}}^{\prime}(\mathrm{t}) ;
\end{gathered}
$$

where $\delta_{i j}(t)$ and $\dot{\delta}_{i j}(t)$ in Eqn. (11) is the total relative displacement and velocity between both buildings with respect to the foundation, respectively. On the other hand, the pounding forces in the transverse direction $\mathrm{F}_{\mathrm{yij}}^{\mathrm{P}}$ have been calculated by the Coulomb friction model $[12,15]$.

\section{Properties of the structures}

\begin{tabular}{|c|c|c|c|c|c|}
\hline \multirow[b]{2}{*}{$\begin{array}{c}\text { Storey } \\
\text { no }\end{array}$} & \multirow{2}{*}{$\begin{array}{l}\text { Height of floor } \\
\text { level, } \mathrm{h}_{\mathrm{i}}, \mathrm{h}_{\mathrm{j}} \\
\text { (m) }\end{array}$} & \multicolumn{2}{|c|}{ Building A } & \multicolumn{2}{|c|}{ Building B } \\
\hline & & $\begin{array}{c}\mathrm{m}_{\mathrm{i}} \times 10^{6} \\
(\mathrm{~kg})\end{array}$ & $\begin{array}{l}\mathrm{k}_{\mathrm{i}} \times 10^{8} \\
(\mathrm{~N} / \mathrm{m})\end{array}$ & $\begin{array}{c}\mathrm{m}_{\mathrm{j}} \times 10^{6} \\
(\mathrm{~m})\end{array}$ & $\begin{array}{l}\mathrm{k}_{\mathrm{j}} \times 10^{8} \\
(\mathrm{~N} / \mathrm{m})\end{array}$ \\
\hline $1 \mathrm{~F}$ & 2.85 & 0.30 & 3.46 & 0.4065 & 5.06 \\
\hline $2 \mathrm{~F}$ & 5.7 & 0.30 & 3.46 & 0.4065 & 3.86 \\
\hline $3 \mathrm{~F}$ & 8.55 & 0.30 & 3.46 & 0.4065 & 3.86 \\
\hline $4 \mathrm{~F}$ & 11.4 & 0.30 & 3.46 & 0.4065 & 3.86 \\
\hline $5 \mathrm{~F}$ & 14.25 & 0.30 & 3.46 & - & - \\
\hline
\end{tabular}

The dimensions of both Building A and Building B are rectangular in plan with $20 \mathrm{~m} \times 15 \mathrm{~m}$ and $25 \mathrm{~m} \times 20 \mathrm{~m}$, the larger plan dimensions being parallel to the longitudinal direction (x) for each building, respectively. The ratio of the base mass to the floor mass of the buildings is 3 for each building. The following basic values describing the structural characteristics in Table 1 have been used:

Table 1: $\quad$ Structural characteristics of buildings.

Moreover, for the translation in the $\mathrm{x}$ and $\mathrm{y}$ axes, twist about the $\mathrm{z}$ axis and rocking about the $\mathrm{x}$ and $\mathrm{y}$ axes, the dimensions of rectangular base of adjacent buildings can be converted into an equivalent circular base having the same area as the plan of each building based on the formulas determined by Richart et al. [10]. Hence, the calculations of the radius of base mass determined by Richart et al. [10] are used with considering translations, rotation and rocking directions, 
herein. The height of each storey is $2.85 \mathrm{~m}$ in both buildings. The moment of inertia of the rigid body for each building about the centroidal axes parallel to the $\mathrm{x}$ and $\mathrm{y}$ axes are evaluated by replacing each floor with a disc of radius $\left(\mathrm{r}_{\mathrm{o}}\right)$. The translational stiffness in the transverse direction and the torsional stiffness about the center of mass for each storey for each building are proportional to the stiffness in the longitudinal direction of the same storey and given by the following formula in Eqn. (12).

$$
\beta_{y}=\frac{k_{y i}}{k_{x i}} \beta_{y}=\frac{k_{y j}}{k_{x j}} \beta_{t}=\frac{k_{\theta i}}{r_{a}^{2} k_{x i}} \beta_{t}=\frac{k_{\theta j}}{r_{b}^{2} k_{x j}}
$$

The ratios, $\beta_{\mathrm{y}}$ and $\beta_{\mathrm{t}}$ are taken as 1.32 and 1.69 for both buildings. The constant of proportionality is evaluated on the basis of $2 \%$ of critical damping in the fundamental mode of superstructures in both buildings. The density of soil medium, $\rho$ and Poisson's ratio, $v$ are taken to be $1922 \mathrm{~kg} / \mathrm{m}^{3}$ and 0.333 , respectively. In order to examine the effectiveness of the rigorous method for the whole SSI systems with using the direct integration method to solve the equations of motion, two soil types are investigated in the range of the shear velocities, $\mathrm{V}_{\mathrm{s}}$ of $65 \mathrm{~m} / \mathrm{sec}$ (soft soil) and $300 \mathrm{~m} / \mathrm{sec}$ (hard soil) have been specifically chosen for this study. Case I $\left(v_{s}=65 \mathrm{~m} / \mathrm{sec}\right)$ and Case II $\left(v_{s}=300\right.$ $\mathrm{m} / \mathrm{sec}$ ) are created for the SSI systems resting on the soft and hard soils in order to investigate the seismic response of the adjacent buildings under large and small SSI effects, respectively. These cases are subjected to the NS and EW components of the 1940 Elcentro earthquake record along the $\mathrm{x}$ and $\mathrm{y}$ axes, respectively. Based on a dimensionless frequency, $\mathrm{a}_{0}$ resulting from $0 \leq \mathrm{a}_{\mathrm{o}}=\omega_{\mathrm{f}} \mathrm{r}_{\mathrm{o}} / \mathrm{v}_{\mathrm{s}} \leq 1.5$, the maximum wave frequencies of both $\mathrm{f}_{\max }=2.1$ $\mathrm{Hz}, 9.7 \mathrm{~Hz}$ of Building A, $1.8 \mathrm{~Hz}$ and $7.8 \mathrm{~Hz}$ of Building B for Case I and Case II, respectively. Most of the energy of the related ground motion is at frequencies less than $1.8 \mathrm{~Hz}$. Hence, by using frequency independent spring and dashpot set for the coupled buildings, the SSI effects of the chosen cases can be conducted effectively. Furthermore, each coupled building has been modelled as reference buildings resting on a rigid base with a similar superstructure. The initial gap, $\mathrm{D}$, between the buildings has been taken as $0.04 \mathrm{~m}$. In order to consider the effect of pounding onto the coupled buildings, when the contact of the buildings in the longitudinal direction has been detected, the pounding forces in the transverse and vertical directions have been applied. For the response time histories of the whole SSI system of the coupled buildings, the rigorous method which uses the direct integration method to solve the equation of motion shown in Eqn. (1) is denoted as rigorous (Rig).

\section{Results of fixed buildings for the SSI effects}

The pounding of the adjacent buildings modelled as elostoplastic multi degree of freedom lumped mass systems with either elastic structural behaviour is studied under the created either Case I or Case II. Firstly, in order to investigate the SSI 
systems on the behaviour of the coupled buildings with the large and small SSI effects, the total response histories of Case I and Case II based on the deformation vectors of both superstructures of the two buildings modelled as elastic systems in Figure 2 and Figure 3, respectively.
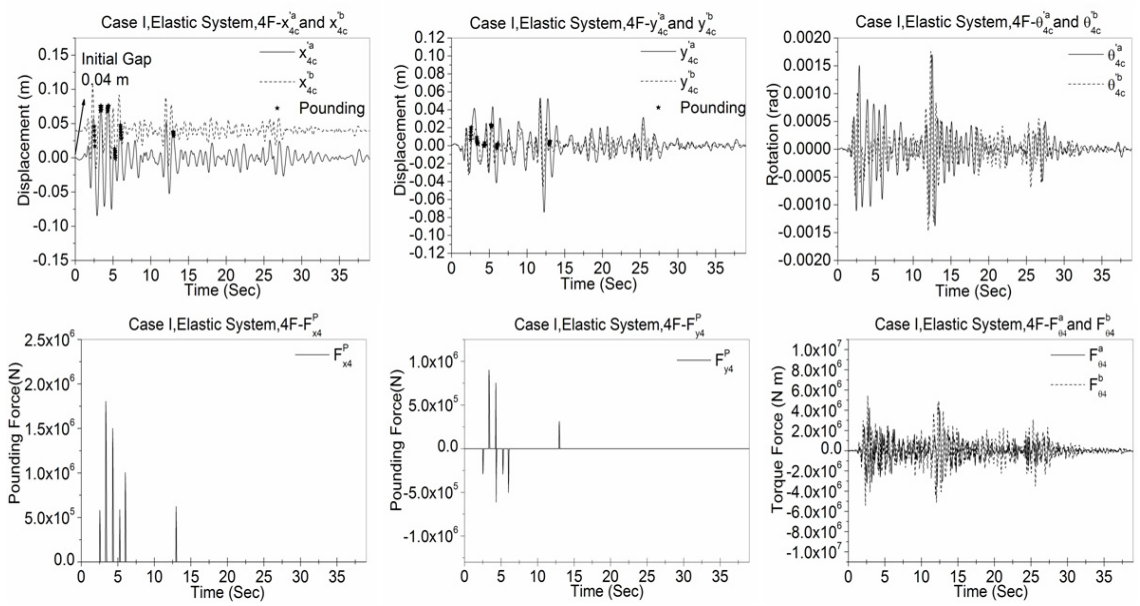

Figure 2: Total response time histories of Case I at the fourth floors of the adjacent buildings modelled as elastic systems under the 1940 Elcentro earthquake.

It can be seen from Figure 2 that both buildings came into contact six times based on the $\mathrm{x}$ directional displacements of the fourth floors during the earthquake. Due to collisions in $\mathrm{x}$ direction and the effect of torque force, the contacts between the buildings in the $y$ axes are developed, although the pounding forces are not severe compared to the highest contact points in the $\mathrm{x}$ direction. While the lighter and more flexible Building A compared to Building $\mathrm{B}$ is subjected to more twist about its $\mathrm{z}$ axes at the top floor levels at the lowest period of the ground motion, the rotations of the top floor of Building B increase after the contact between the buildings. It can be clearly noted from Figure 3 that the number of contact points and the sensitivity of pounding forces in both directions are significantly increased between the buildings as modelled elastic systems. It shows the importance of the SSI effects on the seismic response histories of the adjacent buildings under the two directional 1940 Elcentro Earthquake. The roof twist of both buildings is considerably decreased for Case I compared to that of Case II. Figure 4 and Figure 5 show the deformation in the translations, rotations in the $\mathrm{x}$ and $\mathrm{y}$ axes and twist about the vertical $\mathrm{z}$ axes and of the foundations of the buildings modelled as elastic systems considering Case I and Case II, respectively.

By comparing Figure 4 and Figure 5, it can be seen that the values of the responses at the foundation for Case II (hard soil) are considerably reduced by reason of the small SSI effect. In order to investigate the effect of the buildings 

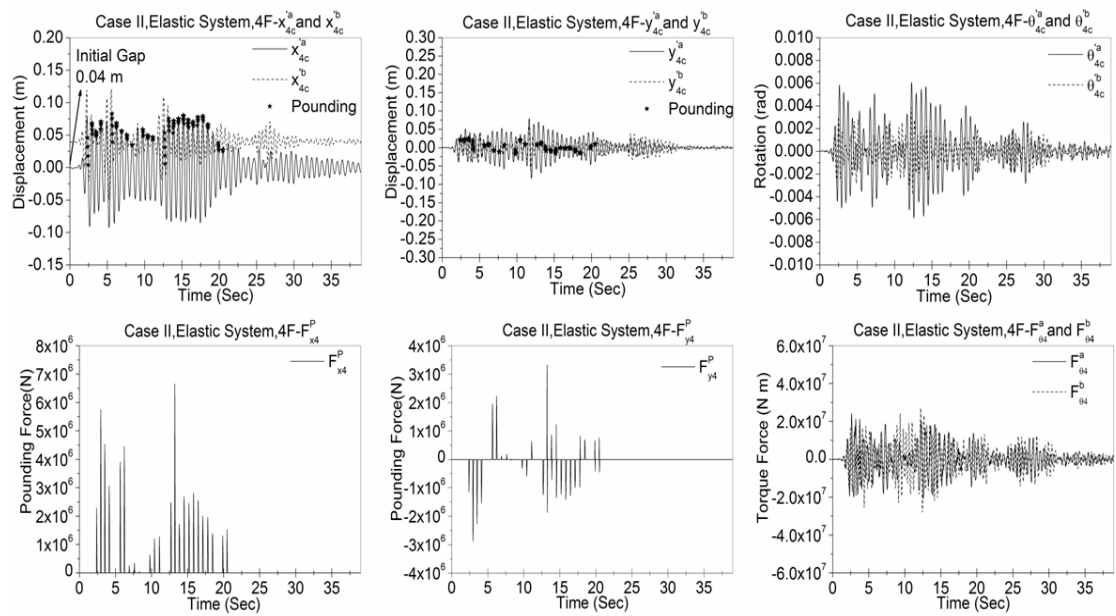

Figure 3: Total response time histories of Case II at the fourth floors of the adjacent buildings modelled as elastic systems under the 1940 Elcentro earthquake.
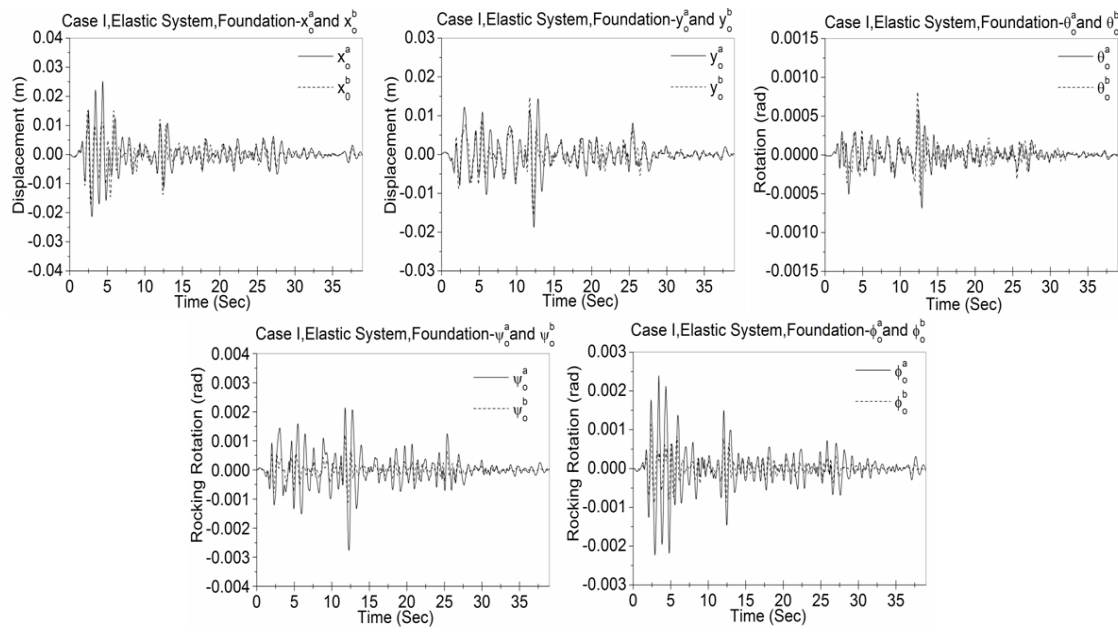

Figure 4: Total response time histories of Case I at the foundations of the adjacent buildings modelled as elastic systems under the 1940 Elcentro earthquake.

modelled as elastic system on the SSI effects, the deformation parameters with considering pounding between the buildings and the SSI forces are conducted here. 


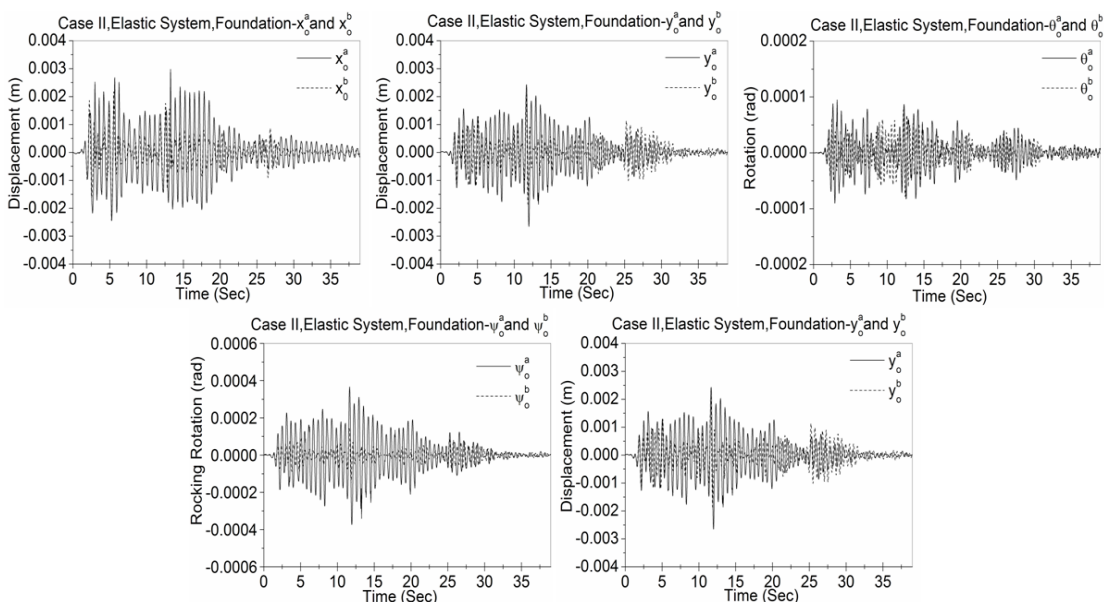

Figure 5: Total response time histories of Case II at the foundations of the adjacent buildings modelled as elastic systems under the 1940 Elcentro earthquake.

\section{Conclusion}

The values of the pounding force and the number of impacts are larger in the Case II compared to Case I. The results of further investigation show that the responses based on deformation vectors of superstructures for each building are significantly reduced by increasing shear wave velocity, while the SSI forces are increased at the foundation of the buildings. At high shear wave velocity, the top floor deformations of couple buildings are slightly on the conservative side. Finally, in increased shear wave velocity, the impact response of buildings is significantly severe.

\section{References}

[1] Hadi, M.N.S., Uz, M.E. Improving the dynamic behaviour of adjacent buildings by connecting them with fluid viscous dampers. in 2nd International Conference on Computational Methods in Structural Dynamics and Earthquake Engineering, COMPDYN 2009. Island of Rhodes, Greece: Institute of Structural Analysis \& Seismic Research National Technical University of Athens, 280, 2009.

[2] Sivakumaran, K.S., Balendra, T. Seismic analysis of asymmetric multistorey buildings including foundation interaction and p-[delta] effects. Engineering Structures 1994; 16(8): 609-624.

[3] Thambirajah, B., Chan Weng, T. \& Seng-Lip, L. Modal damping for torsionally coupled buildings on elastic foundation. Earthquake Engineering \& Structural Dynamics 1982; 10(5): 735-756. 
[4] Thambirajah, B., Chan Weng, T. \& Seng-Lip, L. Vibration of asymmetrical building-foundation systems. Journal of Engineering Mechanics 1983; 109(2): 430-449.

[5] Uz, M.E., Hadi, M.N.S. Dynamic analyses of adjacent buildings connected by fluid viscous dampers. in Seventh World Conference on Earthquake Resistant Engineering Structures ERES VII. Limassol, Cyprus: Wessex Institute of Technology, 139-150, 2009.

[6] Novak, M., Hifnawy, L.E. Effect of soil-structure interaction on damping of structures. Earthquake Engineering \& Structural Dynamics 1983; 11(5): 595-621.

[7] Jui-Liang, L., Keh-Chyuan, T. \& Eduardo, M. Seismic history analysis of asymmetric buildings with soil-structure interaction. Journal of Structural Engineering 2009; 135(2): 101-112.

[8] Uz, M., Hadi, M.N. Investigating the effects of pounding for inelastic base isolated adjacent buildings under earthquake excitations. in Proceedings of the 21st Australian Conference on the Mechanics of Structures and Materials. Melbourne, Victoria, Australia: The Netherlands: CRC Press, pp. 329-334, 2010.

[9] Hadi, M.N.S., Uz, M.E. Inelastic base isolated adjacent buildings under earthquake excitation with the effect of pounding. in The 5th Civil Engineering Conference in the Asian Region and Australasian Structural Engineering Conference 2010 CECAR 5/ASEC 2010. Sydney, Australia, 155-201, 2010.

[10] Richart, F.E., Hall, J.R. \& Woods, R.D. Vibrations of soils and foundations. Prentice-Hall, Englewood Cliffs; 1970.

[11] Jankowski, R. Earthquake-induced pounding between equal height buildings with substantially different dynamic properties. Engineering Structures 2008; 30(10): 2818-2829.

[12] Chopra, A.K. Dynamics of structures. Theory and applications to earthquake engineering. Englewood Cliffs: Prentice-Hall; 1995.

[13] Wriggers, P. Computational contact mechanics with 12 tables. Springer; 2006.

[14] Hadi, M.N., Uz, M. Base isolated adjacent buildings considering the effect of pounding and impact due to earthquakes. in International Congress on Advances in Civil Engineering. Trabzon, Turkey: Eser Ofset Matbaacilik, pp. 227-227, 2010.

[15] Jankowski, R. Experimental study on earthquake-induced pounding between structural elements made of different building materials. Earthquake Engineering \& Structural Dynamics 2010; 39(3): 343-354. 